3. Moscardi, F., Assessment of the application of baculoviruses for control of Lepidoptera. Annu. Rev. Entomol., 1999, 44, 257-289.

4. Melamed-Madjar, V. and Raccah, B., The trans-stadial and vertica transmission of a granulosis virus from the corn borer, Sesamia nonagroides. J. Invertebr. Pathol., 1979, 33, 259-264.

5. Easwaramoorthy, S. and Santhalakshmi, G., Efficacy of granulosis virus in the control of shoot borer, Chilo infuscatellus Snellen. J. Biol. Control, 1988, 2, 26-28.

6. Rao, N. V. and Babu, T. R., Field efficacy of granulosis virus for the control of sugarcane early shoot borer, Chilo infuscatellus Snellen. J. Biol. Control, 2005, 19, 145-148.

7. Subramanian, S., Rabindra, R. J. and Sithanantham, S., Genetic and biological variations among Plutella xylostella granulovirus isolates. Phytoparasitica, 2008, 36, 220-230.

8. Sivakumar, G. et al., Isolation and characterization of indigenous nucleopolyhedrovirus infecting new invasive Fall armyworm Spodoptera frugiperda (J.E. Smith) (Lepidoptera: Noctuidae) in India. Curr. Sci., 2020, 119, 860-864.

9. Polo-PC, User's guide to probit or logit analysis. LeOra Software, Berkeley, 1994

10. Kathleen, A., Tweeten, L. A., Bulla, J. R. and Richard, A. C., Isolation and purification of a granulosis virus from infected larvae of the Indian Meal Moth, Plodia interpunctella. Appl. Environ. Microbiol., 1977, 34, 320-327.

11. Sciocco-Cap, A., Parola, A. D., Goldberg, A. V., Ghiringhelli, P. D. and Romanowski, V., Characterization of a granulovirus isolated from Epinotia aporema Wals. (Lepidoptera: Tortricidae) larvae. Appl. Environ. Microbiol., 2001, 67, 3702-3706.

12. Naveen Kumar, P., Prasad, Y. G., Prabhakar, M., Phanidhara, A. and Venkateshwarlu, B., Granulovirus of semilooper, Achaea janata L. (Lepidoptera: Noctuidae): its bioefficacy and safety in mammalian toxicity tests. J. Biol. Control, 2013, 27, 99-104.

13. Cuartas, P., Barrera, G., Barreto, E. and Villamizar, L., Characterization of a Colombian granulovirus (Baculoviridae: Betabaculovirus) isolated from Spodoptera frugiperda (Lepidoptera: Noctuidae) larvae. Bio. Sci. Tech., 2014, 24, 1265-1285.

14. Ardisson-Araújo, D. M. et al., Betabaculovirus encoding a gp64 homolog. BMC Genomics, 2016, 17; https://doi.org/10.1186/ s 12864-016-2408-9

Received 25 May 2021; revised accepted 14 June 2021

doi: $10.18520 / \mathrm{cs} / \mathrm{v} 121 / \mathrm{i} 4 / 570-573$

\section{Evaluation of probability distribution functions applied to tree diameter in a mixed uneven Kiker (Robinia pseudoacacia) stand of Kashmir Himalaya, India}

\author{
Tariq H. Masoodi ${ }^{1}$, Immad A. Shah ${ }^{2}$, \\ Meraj U. Din Dar ${ }^{2, *}$, Parvez A. Sofi ${ }^{1}$ and \\ Javeed A. Mugloo ${ }^{1}$ \\ ${ }^{1}$ Faculty of Forestry, Sher-e-Kashmir University of Agricultural \\ Sciences and Technology of Kashmir (SKUAST-K), \\ Benhama 191 202, India \\ ${ }^{2}$ Division of Silviculture and Agroforestry, SKUAST-K, \\ Ganderbal 191 201, India
}

Probability distribution is of significance to predict tree distribution and estimate productivity in different ages as well as thinning out in forest stands to ensure optimized and stable stands. Statistical probability distributions, viz. lognormal, Weibull, exponential and gamma were used to fit tree-diameter data generated from the Manasbal forest stand of Kashmir Himalaya, India containing a heterogeneous population of trees with the objective to determine the best probability distribution of tree diameter. To estimate the parameters of the fitted distributions, the method of maximum likelihood was used. The various distributions were evaluated using different goodness-of-fit tests, viz. Kolmogorov-Smirnov, Cramer-von Mises and Anderson-Darling statistics, and the best distribution pertaining to the forest stand was ascertained. Lognormal distribution fitted the data well and could be used in modelling, planning and scheduling the forest stand in the study region.

Keywords: Diameter class, goodness-of-fit statistics, forest stands, probability distribution function, Robinia pseudoacacia.

THE genus Robinia is noteworthy for its numerous uses. Black locust (Robinia pseudoacacia) is part of the Leguminosae family and is known locally as 'Kiker', in Jam$\mathrm{mu}$ and Kashmir, India. It is a rapidly growing species, making it a primary source of biomass fuel in the region. In many native forests where it occurs, $R$. pseudoacacia dominates early forest regeneration ${ }^{1}$. It is a spiny, deciduous tree of medium size, reaching a height of 25-30 mt and a diameter of $80-90 \mathrm{~cm}$ under favourable conditions. Models of forest simulation have been widely used to predict future stand structure. Tree-diameter distribution plays a vital role in simulation modelling. Different probability distributions are being used extensively to model the diameter of trees in the forest stands. Some of the

*For correspondence. (e-mail: mihraj.dar@gmail.com) 
most commonly used distributions are Weibull, lognormal, gamma and exponential.

$R$. pseudoacacia is native to North America, from where it has been introduced into France, Hungary, Belgium, southern Russia, Italy and the Balkan States. In India, it was first introduced in Himachal Pradesh (HP) in 1890 and later in Jammu and Kashmir (J\&K) in 1919, largely to reforest the barren hills. It performed well in the outer Himalaya between 1800 and $3000 \mathrm{~m}$, and in the inner Himalaya at elevations as low as $1050 \mathrm{~m}$ in $\mathrm{HP}^{2}$.

Robinia species have a rough brown to dark grey, longitudinally furrowed bark. The young shoots are smooth, purplish-brown, armed with stout triangular spines in pairs, which persist for some years. Leaves are imparipinnate and $10-15 \mathrm{~cm}$ long. Petioles are swollen at the base, stipules are transformed in spines, leaflets are oval or elliptic in shape, 9-19 in number and $2.5-5.0 \mathrm{~cm}$ long. The flowers are white and fragrant, appear in pendulous axillary racemes up to $20 \mathrm{~cm}$ long on current year's shoots. Pods are $2.5-10 \mathrm{~cm}$ long and $0.9-1.8 \mathrm{~cm}$ broad, flat and dark brown outside, but silvery-white and shining inside bearing 4-16 seeds. The seeds are olive-green to brown, compressed reniform, $5 \mathrm{~mm}$ long.

Robinia ranks high in strength and is considered moderately suitable in shape and size. Tests carried out in India show that Robinia of Kashmir origin is lighter in weight as well as inferior to its USA counterpart in all its properties and uses. Robinia from Srinagar, J\&K, can be classified as heavy, moderately strong and very hard timber, suitable for general construction, flooring, light tool handles, wood poles, fence posts, etc ${ }^{3}$. Its retention of shape and size relative to teak was found to be $73 \%$, taking teak as $100 \%$ (ref. 4). It is also used as fuelwood.

In Hungary, the main source of honey produced commercially is from Robinia crop. The yield of honey per ha at 10 years age of $R$. pseudoacaia was $402 \mathrm{~kg}$; at 15 years $418 \mathrm{~kg}$; at 20 years $407 \mathrm{~kg}$ and at 25 years, $369 \mathrm{~kg}$ (ref. 5).

Distribution studies of tree diameter play a vital role in modelling and simulation studies. According to Rubin et $a l .{ }^{6}$, diameter distributions can be used to indicate whether the density of smaller trees in a stand is sufficient to replace the current population of large trees, and help assess the potential sustainability of forests. Diameter at breast height $(\mathrm{DBH})$ distribution modelling is usually a two-stage process. A probability density function (pdf) is usually fitted at the first stage to the actual diameter distribution and the pdf parameters are regressed against other measured or a priori known stand attributes (parameter prediction method) $)^{7}$. Thomas and $\mathrm{Cao}^{8}$ developed a diameter distribution model for even-aged stands of European beech in Denmark using Weibull distribution. Parameters of the model were estimated by fitting the cumulative density function using a nonlinear least squares procedure. Fallah et al. ${ }^{9}$ showed that regression distribution can determine the diameter distribution of trees. Data collection is difficult in many complex forest stands and often results in data violating simple statistical model assumptions.

Using relevant data distributions in complex forest stands offers a significant solution to this perennial challenge. To evaluate the forest schedule and resources, researchers are particularly interested in predicting the diameter distribution of the forests. Additionally, information on forest distribution is necessary for certain growth models and the associated parameters for proper model identification and fitting. In some cases, none of the distributions is appropriate for all ages. Bullock and Boone $^{10}$ studied diameter distribution of loblolly pine trees (Pinus taeda L.) in Virginia and Northern California, USA. They studied normal, gamma, Weibull and beta distribution for fitting data, and found that sometimes none of the distributions was appropriate for all ages.

The study area, Manasbal is located in Ganderbal district, J\&K. The actual location of the Manasbal catchment (Appendix 1) is defined by $34.0^{\circ} 14^{\prime}-34.0^{\circ} 16^{\prime} \mathrm{N}$ and $740^{\circ} 40^{\prime}-740^{\circ} 43^{\prime} \mathrm{E}$ and has an altitude of about $1551 \mathrm{~m}$ amsl. The climate is generally temperate with severe winter extending from December to March. The region faces a wide temperature range from a minimum of $-4^{\circ} \mathrm{C}$ in winter to a maximum of $33^{\circ} \mathrm{C}$ in summer. The annual precipitation of the area is about $700 \mathrm{~mm}$ and most of the precipitation is received in the form of snow during the winter months. The present study was carried out in the plantation block of Manasbal, maintained by the Faculty of Forestry, SKUAST-Kashmir, Benhama. The tree species in the plantation were Cedrus deodara, Cupressus turlosa, Robinia pseudoacacia and Ulmus villosa. After a survey of the entire area, trees of $R$. pseudoacacia were enumerated and a database on tree diameter at breast height $(\mathrm{DBH})$ was generated. In total, 646 trees were enumerated and DBH was measured using a Jackson diameter tape at a height of $1.37 \mathrm{~m}$. The 646 trees were grouped into five diameter classes. R studio software (version 3.6.3) was used to analyse the data.

The results revealed that Robinia species had a mean diameter of $40.88 \mathrm{~cm}$, with a standard error (mean) of 0.56 and was distributed in the range 15-92. The frequency table and histogram of the diameter classes indicate that the stand is uneven (Table 1 and Figure 1), and the broad range of tree diameter also indicates the same. The distribution is left-skewed indicating that the stand under study is an uneven erratic one. Various distributions belonging to the class of continuous probability distribution were fitted to the diameter data. The estimates obtained on fitting are briefly given here for each distributions. A lognormal distribution is one in which natural $\log$ has a normal distribution with parameters $\mu$ and $\delta$. Estimates from the fitted lognormal distribution computed in R Studio version 1.0.44 are given in Table 2 and Figure 2 shows the resultant plots for the given distribution. 
In Figure 2, the empirical and theoretical density or the kernel plot indicates the distribution of data over continuous interval. The kernel smoothing in the plot allows for a smoother distribution plot by smoothing out the noise. The peak of the density plot indicates the concentration of the values over the interval. Adjacent to the kernel plot is the $Q-Q$ (quantile-quantile) plot, drawn by plotting two sets of quantiles against one another as a graphical method for comparing two probability distributions. On the $Q-Q$ plot, the reference line is dependent on the location and scale parameters of the theoretical distribution. The intercept and slope are equal to the location and scale parameters respectively. A linear pattern in the points indicates that the given family of distributions reasonably describes the empirical data distribution. The $Q-Q$ plot can be used to visually evaluate the similarity of location, scale, and skewness of the two distributions. Similar to the $Q-Q$ plot, the $P-P$ (probability-probability) plot shows cumulative distribution functions (CDFs) of the two distributions (empirical and theoretical) against each other to compare regions of high probability density (centre of distribution) because in these regions the empirical and theoretical CDFs change more rapidly than in the regions of low probability density. The $P-P$ plots can be used to visually evaluate the skewness of the distributions. The concentration of points near the line indicates that both sets of quantiles are from the same distribution, thus suggesting a good fit of lognormal distribution for tree diameter.

The gamma distribution is defined by rate parameter $(\theta)$ and shape parameter $(k)$. The estimates for the two

Table 1. Frequency table of various tree diameter classes

\begin{tabular}{lcc}
\hline Class & Frequency & Relative frequency \\
\hline$<20 \mathrm{~cm}$ & 14 & 0.022 \\
$20-40 \mathrm{~cm}$ & 340 & 0.526 \\
$40-60 \mathrm{~cm}$ & 224 & 0.347 \\
$60-80 \mathrm{~cm}$ & 65 & 0.101 \\
$>80 \mathrm{~cm}$ & 3 & 0.005 \\
Total & 646 & \\
\hline
\end{tabular}

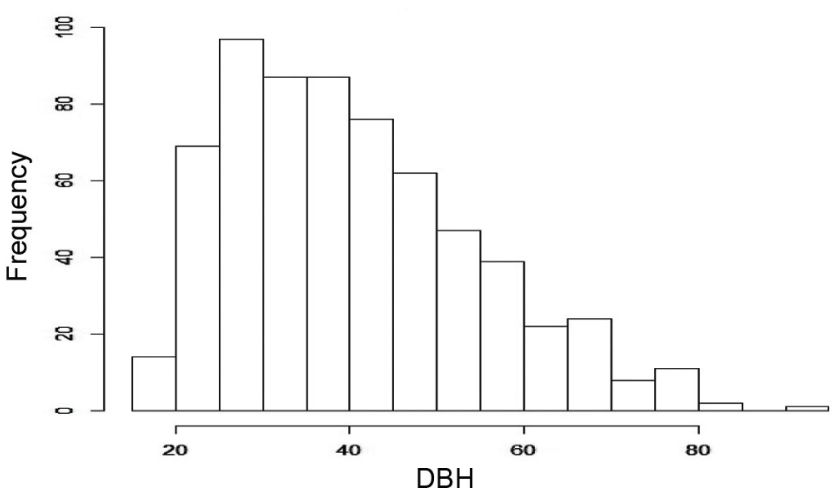

Figure 1. Histogram of tree diameter at breast height. parameters are given in Table 3 and Figure 3 shows the resultant plot for the given distribution. The plots indicate a good fit of the gamma distribution to tree diameter, but show some increase in the Akaike's information criterion (AIC) and Bayesian information criterion (BIC) values compared to those of the lognormal distribution.

Exponential distribution is a special type of gamma distribution with rate parameter $\theta=1 / \lambda$ and scale parameter $=1$. The estimate for rate parameter is given in Table 4 and Figure 4 shows the resultant plot for the given distribution.

The probability plots for the exponential distribution show a deviation of the points from the line, thus indicating a poor fit of the distribution to tree diameter.

Weibull distribution is a type of continuous probability distribution which is defined by the rate parameter $(\theta)$ and Shape parameter $(k)$. The estimates for the parameter are given in Table 5 and Figure 5 shows the resultant plot

Table 2. Summary statistics from lognormal distribution

\begin{tabular}{lrc}
\hline Statistic & Estimate & Standard error \\
\hline Mean log & 3.650 & 0.0138 \\
Standard deviation log & 0.349 & 0.0097 \\
Log likelihood & -2596.017 & \\
Akaike Information Criterion (AIC) & 5196.033 & \\
Bayesian Information Criterion (BIC) & 5204.975 & \\
\hline
\end{tabular}

Table 3. Summary statistics from gamma distribution

\begin{tabular}{lrc}
\hline Statistic & Estimate & Standard error \\
\hline Shape & 8.402 & 0.458 \\
Rate & 0.206 & 0.011 \\
Log likelihood & -2599.811 & \\
AIC & 5203.622 & \\
BIC & 5212.563 & \\
\hline
\end{tabular}

Table 4. Summary statistics from exponential distribution

\begin{tabular}{lrc}
\hline Statistic & Estimate & Standard error \\
\hline Rate & 0.024 & 0.0009 \\
Log likelihood & -3043.111 & \\
AIC & 6088.222 & \\
BIC & 6092.693 & \\
\hline
\end{tabular}

Table 5. Summary statistics from Weibull distribution

\begin{tabular}{lrc}
\hline Statistic & Estimate & Standard error \\
\hline Shape & 3.031 & 0.089 \\
Rate & 45.81 & 0.630 \\
Log likelihood & -2629.033 & \\
AIC & 5262.066 & \\
BIC & 5271.008 & \\
\hline
\end{tabular}


Table 6. Parameters of tests for goodness of fit

\begin{tabular}{|c|c|c|c|c|c|c|c|c|}
\hline \multirow[b]{3}{*}{ Goodness-of-fit test } & \multicolumn{8}{|c|}{ Distribution } \\
\hline & \multicolumn{2}{|c|}{ Lognormal } & \multicolumn{2}{|c|}{ Gamma } & \multicolumn{2}{|c|}{ Exponential } & \multicolumn{2}{|c|}{ Weibull } \\
\hline & Statistic & $P$-value & Statistic & $P$-value & Statistic & $P$-value & Statistic & $P$-value \\
\hline Kolmogorov-Smirnov & 0.055 & 0.42 & 0.068 & 0.12 & 0.380 & 0.04 & 0.082 & 0.04 \\
\hline Cramer-von Mises & 0.248 & 0.31 & 0.352 & 0.34 & 25.903 & 0.05 & 0.871 & 0.01 \\
\hline Anderson-Darling & 1.559 & 0.28 & 2.216 & 0.21 & 128.466 & 0.03 & 5.966 & 0.02 \\
\hline $\mathrm{AIC}$ & \multicolumn{2}{|c|}{5196.033} & \multicolumn{2}{|c|}{5203.622} & \multicolumn{2}{|c|}{6088.222} & \multicolumn{2}{|c|}{5262.066} \\
\hline $\mathrm{BIC}$ & \multicolumn{2}{|c|}{5204.975} & \multicolumn{2}{|c|}{5212.563} & \multicolumn{2}{|c|}{6092.693} & \multicolumn{2}{|c|}{5271.008} \\
\hline
\end{tabular}
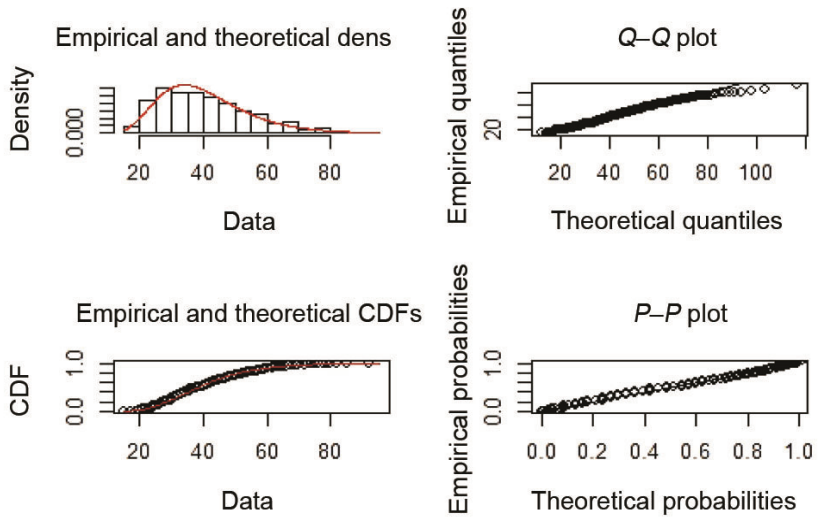

Figure 2. Probability plots from the fitted lognormal distribution.
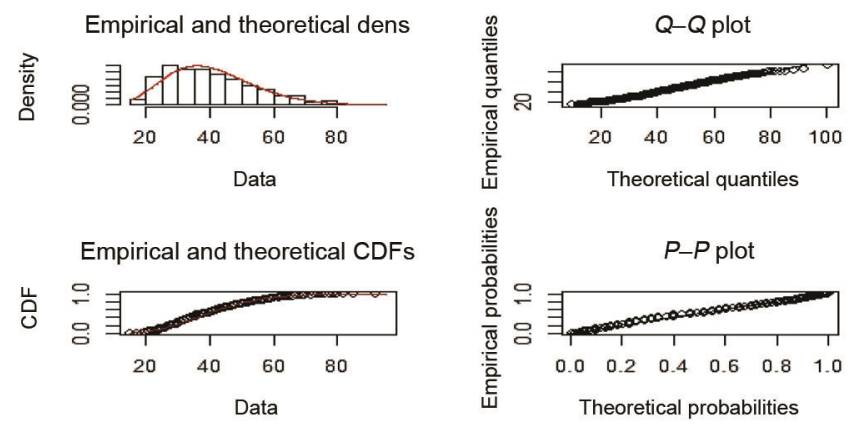

Figure 3. Probability plots from the fitted gamma distribution.
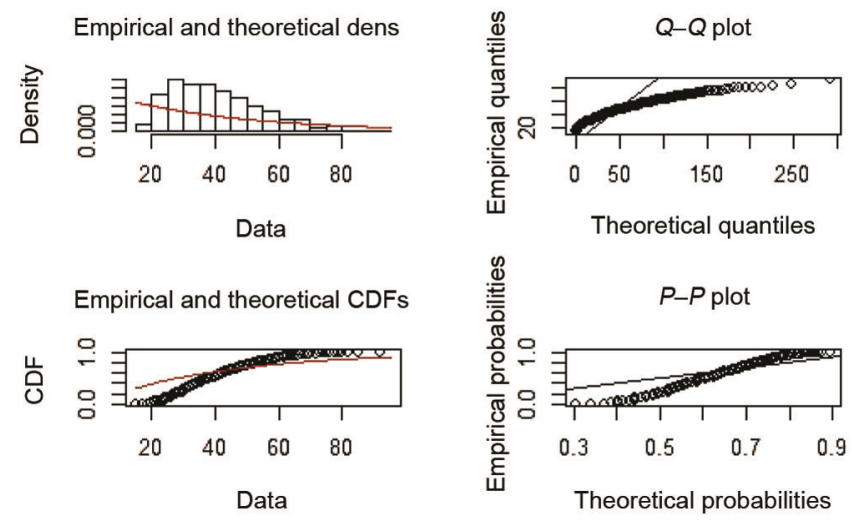

Figure 4. Probability plots from the fitted exponential distribution. for the given distribution. The probability plots for this distribution fall on the line, indicating a good fit but comparably higher $\mathrm{AIC}$ and $\mathrm{BIC}$ values compared to lognormal and gamma distribution.

Often in exploratory research on diameter distribution studies, it is practically difficult to select the best probability distribution that fits the tree diameter based upon the probability plots from various distributions. There is no theoretical reason for the fact that a particular distribution model should be used for all situations ${ }^{11,12}$. It seems that the performance of theoretical distributions is affected by the structure (even- and uneven-aged, and pure and mixed stands), density, development stages and habitat conditions of the studied stands ${ }^{12-15}$. Comparison of actual DBH distributions with the theoretical pdf was evaluated by statistical tests, including KolmogorovSmirnov, Anderson-Darling and Cramer-von Mises test ${ }^{8,12,16-18}$. The purpose of goodness-of-fit statistics is to measure the distance between the fitted parametric distribution and the empirical distribution, e.g. the distance between the fitted cumulative distribution function $F$ and the empirical distribution function $F_{\mathrm{n}}$. The null and alternative hypothesis of the tests were: H0: The data follow the specified distribution. H1: The data do not follow the specified distribution.

Hypothesis tests of the distribution were performed by examining the probability value associated with each of the goodness-of-fit statistic. Also, the lower values of AIC and BIC are good criteria for assessing the best distribution. Table 6 presents the results from the present study.

The results reveal that only lognormal distribution best describes the distribution of DBH of the Robinia species. The study reveals a natural unevenness in the forest stands. Hence estimation of tree distribution in the diameter classes is of great importance and can be used to manage the stands in uneven and aged high forests 9 . Since uneven-aged mixed forests are generally resistant against natural disturbances while providing sustainable production $^{19}$, diameter distribution functions have been widely applied to develop forest growth models. Besides, identification and estimation of quantitative characteristics of tree communities are the initial requirements of forest planning. These models provide insight into the 


\section{RESEARCH COMMUNICATIONS}
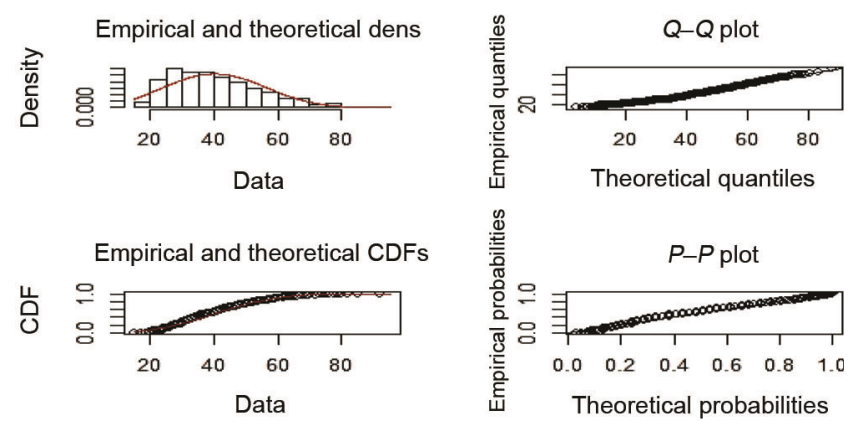

Figure 5. Probability plots from the fitted Weibull distribution.

Appendix 1. Robinia Plantation stand (germplasm conservation-cumexperimental site of the Faculty of Forestry, SKUAST-Kashmir) at Manasbal, Jammu and Kashmir, India
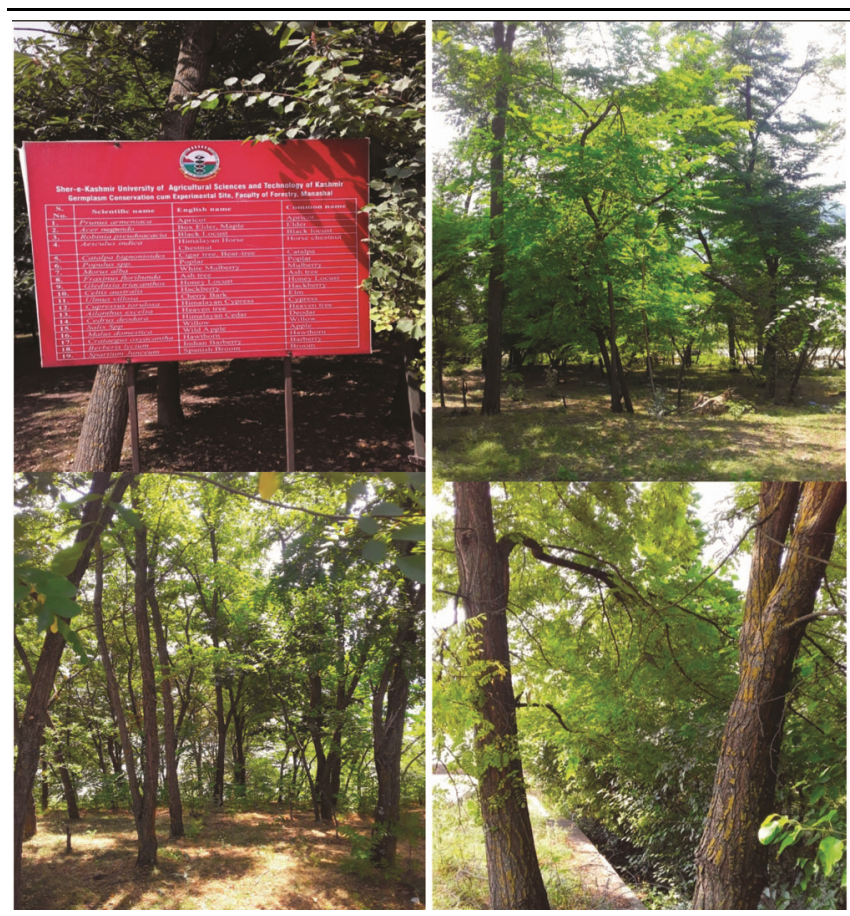

complex causal relationships in forest growth and predict growth processes under various ecological conditions ${ }^{20}$. Statistical distributions provide an important means of studying the diameter distribution of trees, beside graphical representations. From the goodness-of-fit tests, it has been confirmed that lognormal distribution can be used for planning and scheduling forest stands in the region to establish stable stands with maximum production.

1. Boring, L. R. and Swank, W. T., The role of black locust (Robinia pseudoacacia) in forest succession. 1894, 72, 749-766.

2. Luna, R. K., In Plantation Trees, International Book Distributor, Dehradun, 2005, pp. 895-898.

3. Shukla, N. K., Singh, K. R. and Singh, R. S., A note on the physical and mechanical properties of Robinia pseudoacacia. Fraxinus spp. and Ailanthus spp. from Srinagar (J\&K). Indian For., 1986, 112(2), 139-151.
4. Singh, H. P., Pandey, C. N. and Sharma, S. N., Studies on shrinkage behavior of Robinia pseudoacacia timber. Indian For., 1990, 116(10), 832-836.

5. Karestesi, B., Apiculture in forestry environment. In Eighth World Forestry Conference, Jakarta, 16-28 October 1978.

6. Rubin, B. D., Manion, P. D. and Faber-Langendoen, D., Diameter distributions and structural sustainability in forests. For. Ecol. Manage, 2006, 222, 427-438.

7. Nanos, N. and Montero, G, Geostatistical predictions of height/ diameter models. For. Ecol. Manage., 2002, 161, 147-158.

8. Thomas, N. L. and Cao, Q. V., A diameter distribution model for even aged beech in Denmark. For. Ecol. Manage., 2006, 231, $218-225$.

9. Fallah, A., Zobeiry, M., Jaziriee, M. H. and Marvie, M., A study of tree distribution in Diameter classes in natural forest of Iran (case study: Liresara Forest). Iran. J. Nat. Resour., 2006, 53(3), 251-260.

10. Bullock, B. P. and Boone, E., Deriving tree diameter distributions using Bayesian models averaging. Nanos. For. Ecol. Manage., 2007, 242, 127-132.

11. Wang, M., Rennolls, K. and Tang, S., Bivariate distribution modeling of tree diameters and height: dependency modeling using copulas. For. Sci., 2008, 54(3), 284-229.

12. Amanzadeh, B., Sagheb-Talebi, K., Fadaei Khoshkebijari, F., Khanjani Shiraz, B. and Hemmati, A., Evaluation of different statistical distributions for estimation of diameter distribution within forest development stage in Shafaroud Beech stands. Iran. J. For. Poplar Res., 2011, 19(2), 254-257 (in Persian).

13. Bailey, R. L. and Dell, T. R., Quantifying diameter distributions with the Weibull function. For. Sci., 1972, 19, 97-104.

14. Amanzadeh, B., Investigation on structure, natural stand development stages and ecological characteristics of canopy gaps in mixed stands of Nav Forests, Asalem, Ph.D. thesis, Sari Agricultural Sciences and Natural Resources University, Mazandaran Province, Sari, Iran, 2015, p. 215.

15. Podlaski, R., Suitability of the selected statistical distributions for fitting diameter data in distinguished development stages and phases of near-natural mixed forests in the Swietokrzyski National Park (Poland). For. Ecol. Manage., 2006, 236, 393-402.

16. Khongor, Ts., Lin, C., Narangarav, D. and Tsogt, Z., Larch stand structure analysis of boreal forest in Mongolia. International Conference on Environmental Science and Technology (ICEST2011), Singapore. IACSIT Press, 2011, 6, 2123-2127.

17. Tsogt, K., Zandraabal, T. and Lin, C., Diameter and height distributions of natural even-aged pine forests (Pinus sylvestris) in Western Khentey, Mongolia. Taiwan J. For. Sci., 2013, 28(1), 29 41.

18. Humphrey, A. I. and Godwin, O. E., Modeling diameter distribution of the tropical rainforest in Oban Forest Reserve. J. Environ. Ecol., 2014, 5(2), 130-143 (in Nigerian).

19. Alijani, V., Vagheb-Talebi, K. and Akhavan, R., Quantifying structure of intact beech (Ficus orientalis Lipsky) stands at different development stages (case study: Kelardast area, Manzandaran) stands. Iran. J. Forest Poplar Res., 2014, 21(3), 396-410.

20. Merganic, J. and Sterba, H., Characterization of diameter distribution using the Weibull function: method of moments. Eur. J. For Res., 2006, 125, 427-439.

ACKNOWLEDGEMENT. We thank Prof. T. H. Masoodi (Dean, Faculty of Forestry Benhama Ganderbal) for guidance.

Received 25 January 2021; revised accepted 6 July 2021

doi: $10.18520 / \mathrm{cs} / \mathrm{v} 121 / \mathrm{i} 4 / 573-577$ 